\title{
Dimensions of Entrepreneurial Competencies of Agribusiness Managers in Niger Delta Region of Nigeria
}

\author{
By Edet Joshua Udoh* \\ Emem Bassey Inyang ${ }^{\dagger}$ \\ Blessing Akudo Oguzie
}

Challenges to business survival in developing regions have been noted to be different from those in the developed regions of the world. Thus, the competencies among the business managers in these regions differ considerably in magnitude and direction over eighteen traits that can influence the quality of performances technically; shortfall or proficiency of managers hinges on the quality of exhibition of these traits. Within this context, it became imperative to investigate the attributes of the enterprise managers who have successfully managed their enterprise over challenging business environment. This study assessed the entrepreneurial competencies of agribusiness operators in the Niger Delta Region of Nigeria. A sample size of 85 respondents were selected through snowballing sampling procedure from bakery and restaurant enterprises. Data collected were analyzed using factor analysis. Results reveal that competencies like proactively, networking, and self-efficacy, willingness to take risk, creative thinking and willingness to learn were being possessed by the firm managers. According to the results, it is of utmost importance for entrepreneurs to develop some specific competencies in order to obtain a higher performance.

Keywords: Competency, Entrepreneurial, Agribusiness, Food, Processors, Managers, Dimensions

\section{Introduction}

Quest for attainment of food security has become major policy thrust of the Federal and State Government in Nigeria. The situation has attracted major international development focus due to its relevance to attainment of the millennium development goals. The process of sustaining food security is multifaceted and complex aside production; quality processing of agro produce does contribute to availability, affordability and accessibility of food among households. Therefore, the level of organisation within food processing industry in any economy is critical and it sets the pace and status of ensuring food security

\footnotetext{
* Department of Agricultural Economics and Extension, Faculty of Agriculture, University of Uyo, Nigeria.

${ }^{\dagger}$ Lecturer, Department of Agricultural Economics and Extension, Faculty of Agriculture, University of Uyo, Nigeria.

$\$$ Department of Agricultural Economics and Extension, Faculty of Agriculture, University of Uyo, Nigeria.
} 
in quality and spatial distribution. Currently, the level of organisation within food industry cluster across micro, small, medium and very few large scale enterprises in the study area and the majority of the food processing enterprise possess the SMEDAN classification of the small and medium size enterprises (Fasua, 2006; Olajide, Ogundele, Adeoye and Akinlabi ,2008; CBN, 2001, Dannson, Ezedinma, Wanmbia, Bashasha, Kirsten and Satorius ,2004 and Gabbot and Hogg, 1997)).

Food processing being agribusiness, requires certain resources and capacities necessary to venture into the food industry. Business continuity in this sector requires quality human capital in managerial proficiency to guarantee quality performance particularly the entrepreneurial competencies of agribusiness managers. Though, the medium and large scale firms may have a pool of line and staff managers to continually buffer the critical path towards business survival, the situation among the micro and small firms appears to be at disadvantage in terms of technical support accessibility within the firms. This gap tends to explain the massive enterprise survival bankruptcy and shut ups in the developing economy (Covin and Slevin, 1989 and Entrialgo, Fernanderz and. Vazquez, 2001). Survival and success of the business, entrepreneurs require skills and abilities. Bird (1995) maintained that entrepreneurial competencies are defined as underlying characteristics possessed by a person which result in new ventures creation, survival, and/or growth.

It was suggested that the entrepreneur's demographic characteristics, attitudinal, behavioural, managerial and technical competencies are often cited as the most influential factors related to the performance of small and medium sized enterprises (Man, Lau and Chan, 2002). Literatures have further revealed that performances of small firms are influenced by arrays of factors driven by environmental conditions (Naman and Slevin, 1993; Tsai, MacMillan and Low, 1991; Zahra, 1993 and Stoke and Wilson, 2006). Operating under these constraints induces special adaptive skills which are required for competitive advantage and sustainable enterprise survival. Several studies have been done on the influence of entrepreneurial competencies on SMEs but few have specifically focused on the influence of entrepreneurial competencies on the performance of small firms in Uyo Metropolis or Uyo Capital city. Most of the food service units are not corporately registered with federal government aside registration with the local authority driven by generation of tax revenue. There exist no dataset for times series studies of this sector of economy. Based on personal observation, there is massive entry and exit within the food service sector. Ascertaining the population of this food service players thus became a bit cumbersome as hardly do majority of the SMEs exist beyond six years in same location. Umoh (2015) in his study of tracking corporate existence of 225 listed business organisations with Corporate Affairs Corporation of Nigeria between 1983 and 2009 in Akwa Ibom State, he opined that there was $81 \%$ mortality rate of business organisations in the study area. With regards to SMEs survival status survey of 334 in the study area, he admitted that only $13.8 \%$ were optimally functional in its operations while somewhat functional were $76.3 \%$, less functional $(6.6 \%)$ and virtually abandoned (3.3\%). Thus, with virtually limited studies on the factors 
responsible for functionality of survived SMEs in an uncertain business settings and this study sought to fill the research gap. The specific objectives are to:

1. Examine the institutional characteristics of the small and medium enterprise operators in Uyo Metropolis.

2. Evaluate the entrepreneurial competencies possessed by the agribusiness operators in the study area.

\section{Theoretical Framework}

This study draws it concept from the core competency theory, which Prahalad and Hamel in 1990 defined as the collective learning in the organization, especially how to coordinate diverse production skills and integrate multiple streams technologies. Organization should be fully aware of potentials and core competencies so as to harness huge resources in their fold. Core competencies can also be seen as an expertise or mental capacity advantage a firm has over its competitors and they are not necessarily products or tangible resources (Quinn, 1999 and Bird, 1995). The core competency theory therefore suggests that all firms would likely be functional and would gain meaningful profit margin if managers are imbued with certain special proficiencies and are technically harnessed.

\section{Meta Analysis of Entrepreneurial Competencies of Small Scale Enterprise Operators}

A number of attributes have been suggested as predicators of central behaviour with some degree of consensus on managers' competencies. These studies have tended to examine in some detail the synonyms and adjectives used to described entrepreneurs since they tend to identify what makes an entrepreneurial personality characterized by certain traits. The entrepreneur is the individual that identifies the opportunity, gather the necessary resources, creates, and is ultimately responsible for the performance of the organization. However, the above definitions cannot discount the importance of the traits and characteristics of the entrepreneur from the perspective of their propensity to act and the influence of the social, cultural, psychological, political and economic contextual factors. For instance, such factors as the need for achievement (McClelland, 1965); risk taking propensity (Brockhaus, 1980); locus of control (Brockhaus, 1982); desire for personal control of business (Sexton and Bowman, 1983); opportunity seeking, risk taking and innovation, demand for efficiency and product quality, persistence in searching for suitable technology, commitment, information seeking to enhance production efficiency, goal setting, systematic planning and monitoring, persuasion and networking with trade groups and associations, support institutions and large-scale industries (McClelland, 1969) 
and United Nations Centre for Transnational Corporation (UNCTC,1988) have been identified and examined as possible traits or characteristics associated with entrepreneurial behaviour.

In addition, other background factors or human capital related to individual personality have been discussed. Some of these include previous employment (Storey, 1982); family background (Scott and Twoney, 1988); age and gender (Buttner and Rosen, 1989); education (Storey, 1982) and religion (Weber, 1930) as cited in Tonge (2002). Altogether, the combination of personal characteristics with background factors or human capital makes some individuals more likely entrepreneurial candidates than others (Tonge, 2002). In the context of a small business enterprise, these competencies are normally studied as characteristics of the entrepreneur, who owns and actively manages the business (Gibb, 2005; McGregor \& Tweed, 2001). Tapan (2002) in his paper based on the empirical research conducted in four Indian states on industrial units which are often categorised under the small-scale sector made an attempt to explain the relationship that exists among various socio-economic variables with different success levels among the enterprises. He has found that there are associations between the success levels of an enterprise with factors like technical education of the entrepreneur, occupational background of parents, previous background of the entrepreneur and capability to arrange working capital.

Cheskin (2000) has observed in his empirical study that men and women differ significantly in their networking skills. Men spend more time networking in order to further their business goals than do women. This doesn't necessarily indicate that women are less social. In fact women value their ability to develop relationships. It may be that men integrate business into their social lives more than women do. Women and men shared the same motivations driving them in their entrepreneurial pursuits. Furthermore, successful women and men have agreed on and personify majority of attributes associated with entrepreneurs which included persistence, a positive attitude, creativity, and vision. However women value courage, independence, strength, and fearlessness more highly than men do. These value differences are likely a reflection of the attitudes women have had to maximize in order to succeed in the business world. Therefore, to summarize the model for this research study, researchers argue that one of the main factors influencing a new small-scale manufacturing industry creation and subsequent performance is an interactive process in which entrepreneurial personal characteristics interact with human capital, particularly education (technical and management), and other salient factors in the environment to influence decisions concerning new venture creation, performance and growth. However, Rasheed (2002) in his assertions suggested that some entrepreneurial personality traits are very relevant; need for achievement, creativity and initiative, risk taking and setting objectives, selfconfidence and internal locus of control, need for independence and autonomy, motivation, energy, commitment and persistence.

In the Niger Delta region, there is growing concern of economic empowerment, self employment and the desire to reduce poverty through entrepreneurial consolidation (Aremu and Adeyemi 2011). But, when these 
enterprises hardly survive beyond few years of existence (Umoh, 2015) and world over, statistics have shown that two third of all businesses worldwide fail to survive into second generation (Beckhard and Pritchard, 1993 and Handler, 1994). The business environment has given serious concern to understand the dimensions of entrepreneurial competencies that keeps surviving enterprise running over this period. Therefore, what among the personality and characteristics of the entrepreneurs are needed to assess their technical and managerial competence for small business start-up, growth and sustainability.

\section{Methodology}

This study was conducted in Uyo Metropolis which is a capital city in the niger Delta Region of Nigeria and is the capital of Akwa Ibom State. Uyo capital city has a population of about 436,606 according to the 2006 Nigerian census and had increased substantially over the last decade. It is located between latitude $5^{0} 35 \mathrm{~N}$ and longitude $7^{0} 50 \mathrm{E}$. Uyo Metropolis occupies an estimated landmass of 115 square kilometres. It is notable for various types of small, medium and large-scale manufacturing industries However, the vast majority of indigenous enterprises in Nigeria are owner-managed private small-scale businesses. The population of the study included all the managers the bakery ad restaurant small and medium scale enterprises operating in Uyo capital city. The total population is undefined due to no data set on food services SMEs in the Akwa Ibom State or Local government Area. Based on situation, the study employed snowball sampling procedure in the selection of location and respondents in order to map the study population which also served as sample size. From the city, eighty-five (85) small scale agribusinesses were identified consisting of 45 bakeries and 40 restaurants and managers were used in the study. Basically primary source of data collection was employed by the study; a structured questionnaire was used to gather primary data from the respondents. Factor analysis was used to satisfy the objective of the study.

\section{Results and Discussion \\ Institutional/personal Characteristics of Firms/managers}

Table 1 presents some of the institution and personal characteristics of the enterprises and their managers. This result reveals that most respondents were in their active age and this contributes to their ability to learn new technologies and this corroborates the assertion, that actual and perceived entrepreneurial skills are acquired overtime and consequently age has an impact on entrepreneurship. With regards to sex ratio composition (male: female), it was observed that for restaurants females are the ones who manage the enterprise while for bakery, males are mostly the one managing the business. This is a confirmation that women tended to operate enterprises associated with traditional women's roles, such as restaurants, retail shop, hotels. On average, the business 
managers have been in managerial position for about 6 and 7 years for bakery and restaurant respectively. About $77 \%$ and $45 \%$ of the surveyed bakery and restaurants respectively have registered their business with Corporate Affairs Commission. About $89 \%$ of the bakeries have membership of two professional unions namely: Association of Fast Food Confectioners in Nigeria and Bakers' Association of Nigeria while for restaurant only $32 \%$ agreed to be members of National Association of Restaurant Owners. After running the business, about $44 \%$ and $2.5 \%$ of respective bakery and restaurant enterprises has received managerial training, and according to King and McGrath, (2002) those with more education and training are more likely to be successful in the SME sector. As such, for small businesses to do well, entrepreneurs need to be well informed in terms of skills and management.

Table 1. Institutional/personal Characteristics of Firms/managers

\begin{tabular}{lll}
\hline Description & Bakery & Restaurant \\
\cline { 2 - 3 } & Mean value & Mean value \\
\hline Age of the business owner & 40.4 & 38.5 \\
Sex ratio (Male : Female) & $62: 38$ & $15: 85$ \\
Experience in the business & 9.02 & 6.75 \\
Managerial years of experience & 5.89 & 6.75 \\
Registration status & $77.8 \%$ & $45 \%$ \\
Membership of professional union & $88.9 \%$ & $32.5 \%$ \\
Managerial training received & $44.4 \%$ & $2.5 \%$ \\
\hline
\end{tabular}

Table 2. Result of the Tenability and Sustainability of the Instrument for Restaurant

\begin{tabular}{lll}
\hline KMO and Bartlett's Test & \\
\hline \multicolumn{2}{l}{ Kaiser-Meyer-Olkin Measure of Sampling Adequacy. } & .522 \\
Bartlett's Test of Sphericity & Approx. Chi-Square & 260.506 \\
& Df & 153 \\
& Sig. & .000 \\
\hline
\end{tabular}

\section{Evaluation of the Entrepreneurial Competencies Possessed by the Small Scale Agribusiness Managers}

In order to ascertain the entrepreneurial competencies possessed by the firm managers in the study area, thirty seven (37) items were initially generated and through principal component approach reduced to major and sizeable significant number of factors using Eigen value criterion of greater than 1 . 
Table 3. Principal Components Factor Analysis for Positioning Typology Items Factor Loadings

Items

\begin{tabular}{llllllll}
\hline 1 & 2 & 3 & 4 & 5 & 6 & 7 & CEI
\end{tabular}

Develop long-term

1 trusting relationships

.895

.859

with others

2 Communicate with my staff effectively

3 Communicate with my customers effectively

4 Develop calendar of activities

Maintain a positive

5 attitude towards the challenges that occur

Redesign the department and/or

6 enterprise to better meet long-term objectives and changes

Be conversant with the

7 latest technological innovation in the business

8 Plan the operations of the business.

9 Lead subordinates

10 Interact intellectually with my customers

11 Interact intellectually with my staff

12 Identify goods or services customers want

${ }_{13}$ Coordinate tasks effectively

Understand what others

14 mean by their words and actions.

15 Negotiate with others

16 Motivate my customers 
17 Organize resources

In dealing with our competitors, we

18 typically initiate

actions, which competitors then responded to.

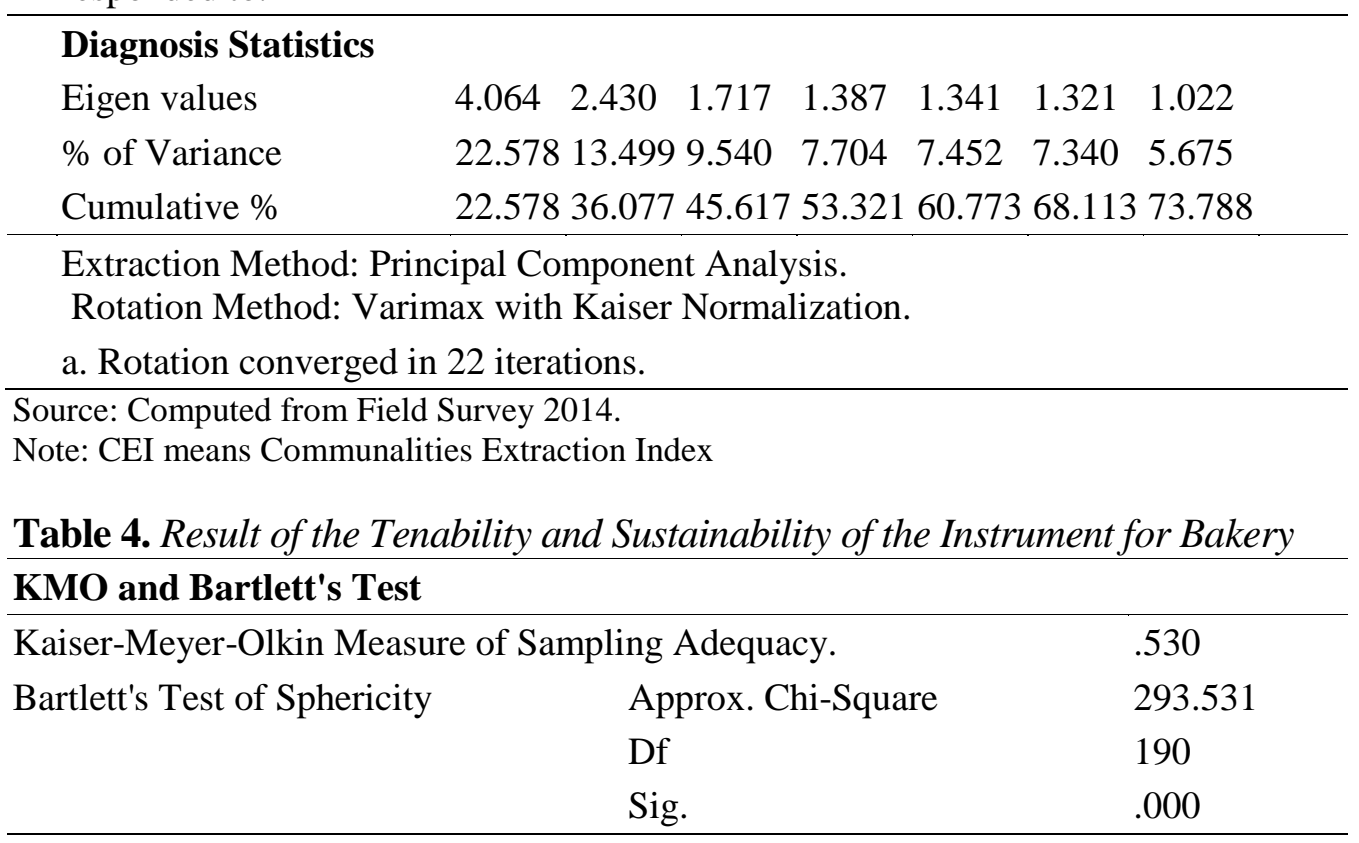

The instrument was first subjected to KMO and Bartlett's Test to check for the tenability and sustainability of the instrument and to confirm the appropriateness of the data for exploratory factor analysis. Given that the aim was to identify the minimum number of factors that would account for the maximum portion of the variance of the original items, principal component analysis was selected (Nunnally, 1978) to reduce the number of factors where the Eigen value is greater than 1, and a cumulative percentage of variance explained being greater than $50 \%$, were the criteria used in determining the number of factors. On the basis of these criteria, 7 factors were extracted (see Table 3 and 5) and explains $74 \%$ and $68 \%$ of the variance in the data for restaurant and bakery enterprises respectively. This 7 factor model will be used in the subsequent analyses. Furthermore, the high communality column in Tables 3 and 5 indicates evidence of overall significance of the solution, that is, the communality provides strong variance between the variables in the analysis. 
Table 5. Principal Components Factor Analysis for Positioning Typology Items Rotated Component Matrix

\begin{tabular}{|c|c|c|c|c|c|c|c|c|}
\hline & \multirow[t]{2}{*}{ Items } & \multicolumn{7}{|c|}{ Component } \\
\hline & & 1 & 2 & 3 & 4 & 5 & 6 & 7 \\
\hline 1 & $\begin{array}{l}\text { Communicate with my staff } \\
\text { effectively }\end{array}$ & .879 & & & & & & .873 \\
\hline 2 & $\begin{array}{l}\text { Develop long-term trusting } \\
\text { relationships with others }\end{array}$ & .768 & & & & & & .564 \\
\hline 3 & Motivate my customers & .733 & & & & & & .622 \\
\hline 4 & $\begin{array}{l}\text { Identify goods or services } \\
\text { customers want }\end{array}$ & & .840 & & & & & .598 \\
\hline 5 & $\begin{array}{l}\text { Interact intellectually with } \\
\text { my customers }\end{array}$ & & .684 & & & & & .772 \\
\hline 6 & $\begin{array}{l}\text { Perceive unmet consumer } \\
\text { needs }\end{array}$ & & .623 & & & & & .775 \\
\hline 7 & Lead subordinates & & & .821 & & & & .766 \\
\hline 8 & $\begin{array}{l}\text { Maintain a positive attitude } \\
\text { towards the challenges that } \\
\text { occur }\end{array}$ & & & .686 & & & & .768 \\
\hline 9 & $\begin{array}{l}\text { Communicate with my } \\
\text { customers effectively }\end{array}$ & & & .485 & & & & .757 \\
\hline 10 & $\begin{array}{l}\text { Keep organization running } \\
\text { smoothly }\end{array}$ & & & & .829 & & & .782 \\
\hline 11 & $\begin{array}{l}\text { Learn to act in advance to } \\
\text { deal with an expected } \\
\text { difficulty or change. }\end{array}$ & & & & .611 & & & .555 \\
\hline 12 & $\begin{array}{l}\text { Seize high-quality business } \\
\text { opportunities }\end{array}$ & & & & .568 & & & .687 \\
\hline 13 & $\begin{array}{l}\text { Redesign the department } \\
\text { and/or enterprise to better } \\
\text { meet long-term objectives } \\
\text { and changes }\end{array}$ & & & & & .727 & & .754 \\
\hline 14 & $\begin{array}{l}\text { Take reasonable job-related } \\
\text { risks }\end{array}$ & & & & & .725 & & .558 \\
\hline 15 & Coordinate tasks effectively & & & & & & .690 & .543 \\
\hline 16 & $\begin{array}{l}\text { Develop calendar of } \\
\text { activities }\end{array}$ & & & & & & .649 & .615 \\
\hline
\end{tabular}


17 Organize resources .643

Be conversant with the

18 latest technological

innovation in the

business

Actively look for

${ }_{19}$ products or services

that provide real benefit

to staff

20 Keep up to date in my field

\section{Diagnosis Statistics}

$\begin{array}{llllllll}\text { Eigen values } & 4.491 & 1.959 & 1.814 & 1.523 & 1.374 & 1.223 & 1.160 \\ \text { \% of Variance } & 22.457 & 9.793 & 9.069 & 7.614 & 6.868 & 6.113 & 5.799 \\ \text { Cumulative \% } & 22.457 & 32.250 & 41.319 & 48.933 & 55.800 & 61.913 & 67.713\end{array}$

Extraction Method: Principal Component Analysis.

Rotation Method: Varimax with Kaiser Normalization.

a. Rotation converged in 6 iterations.

Source: Computed from Field Survey, 2014.

Note: CEI means Communalities Extraction Index

Table 6. Showing the Names of the Major Dimensions of Entrepreneurial Competencies Possessed by Restaurant and Bakery Managers

For restaurant For bakery

Factor 1: effective interpersonal skills

Factor 2: adaptability and flexibility

Factor 3: effective technical knowledge

Factor 4: effective social competency

Factor 5: effective analytical reasoning

Factor 6: networking

Factor 7: proactivity

Factor 1: effective social competency

Factor 2: creative thinking

Factor 3: self-efficacy

Factor 4: proactivity

Factor 5: willingness to take risk

Factor 6: planning and organizing

Factor 7:willingness to learn

In order to obtain a clear picture of the structure, the initial solution was rotated, no prior assumption in terms of factor dependence was made and consequently an oblique rotation was applied to the data (Parasuraman, Zeithaml and Berry 1988, Kinnear and Gray 1997). On the basis of the sample size, the criterion for the significance of factor loading for the extracted common factors was stipulated to be greater than the absolute value of 0.5 suggested by Hair, Anderson, Tatham, Black (1998). Communality was also examined in order to assess how much variance of each item was accounted for by the extracted factors and to shed light into possible elimination of items (given the lack of accepted guidelines, a cut-off value of 0.5 was used). The solution presented in Tables 2 and 4 leads to the following conclusions: 
a) All of the statements meet the communality criterion.

b) The loadings associated with the majority (i.e. 18 of the 37 items for restaurant and 20 of 37 items for bakery) of the items were above the 0.5 specified criterions.

\section{Naming of Major Dimension of Entrepreneurial Competencies Possessed by the Firm Managers}

The results of factor analysis on tables 3 and 5, only seven mutually exclusive and major patterns were generated by the factor analysis procedure. The major dimensions as shown in Tables 4 and 6 are named as follows:

\section{For Bakery}

\section{Factor 1: Effective Social Competency}

This factor accounted for $22.4 \%$ of the total variation within the distribution of the entrepreneurial competency variables and of twenty (20) variables used in the analysis, three (3) loaded highly on this factor. These were: communicate with my staff effectively (.879), develop long-term trusting relationships with others (.768) and motivate my customers (.733). This factor was the most important factor among seven dimensions extracted. By implication, the major competencies possessed by the managers are centred on the three variables in this factor.

\section{Factor 2: Creative Thinking}

Variables within this factor were associated with creative thinking. Three variables loaded highly on this factor namely: identity goods or services customers want (.840), interact intellectually with my customers (.684) and perceive unmet consumer needs (.623). This factor accounted for $9.79 \%$ of the variation in the data set.

\section{Factor 3: Self Efficacy}

This factor was responsible for $9.06 \%$ of the variation in the distribution of competencies variables. It is loaded positively and highly on three major variables that were associated with self-efficacy. These variables were: lead subordinates (.821), maintain a positive attitude towards the challenges that occur (.686) and communicate with my customers effectively (.485).

\section{Factor 4: Proactivity}

Factor 4 has been named "proactivity" due to its high loadings on keep organization running smoothly (.829), learn to act in advance to deal with an 
expected difficulty or change (.611) and seize high-quality business opportunities (.568). This factor accounted for $7.61 \%$ of the variation in the data set.

\section{Factor 5: Willingness to Take Risk}

This factor accounted for $6.86 \%$ of the variation in the data set. Only two variables loaded highly on this factor. They were: redesign the department and/ or enterprise to better meet long-term objectives and changes (.727) and take reasonable job-related risk (.725).

\section{Factor 6: Planning and Organizing}

Four variables loaded highly on this factor. These variables were; coordinate task effectively (.690), develop calendar of activities (.649), organize resources (.497) and be conversant with the latest technological innovation in the business (.468). It accounted for $6.11 \%$ of the variation in the data set.

\section{Factor 7: Willingness to Learn}

This factor was the least factor, it accounted for only $5.79 \%$ of the variation in the data set. This factor was named due to both the positive and negative loadings on actively look for products or services that provide real benefit to staff (.835) and keep up to date in my field (-.596).

\section{For Restaurant}

\section{Factor 1: Effective Interpersonal Skills}

This factor accounted for $22.57 \%$ of the total variation within the distribution of the entrepreneurial competency variables and of eighteen (18) variables used in the analysis, three (3) loaded highly on this factor. These were: develop long-term trusting relationships with others (.895), communicate with my staff effectively (.823) and communicate with my customers effectively (.598). This factor was the most important factor among seven dimensions extracted. By implication, the major competencies possessed by the managers are centred on the three variables in this factor.

\section{Factor 2: Adaptability and Flexibility}

Variables within this factor were associated with adaptability and flexibility. Three variables loaded highly on this factor namely: develop calendar of activities (.878), maintain a positive attitude towards the challenges that occur (.589) and redesign the department and/or enterprise to better meet long-term objectives and changes (.517). This factor accounted for $13.49 \%$ of the variation in the data set. 


\section{Factor 3: Effective Technical Knowledge}

This factor was responsible for $9.54 \%$ of the variation in the distribution of competencies variables. It is loaded positively and highly on three major variables that were associated with effective technical knowledge. These variables were: be conversant with the latest technological innovation in the business (.819), plan the operations of the business (.727) and lead subordinates (.639).

\section{Factor 4: Effective Social Competency}

Factor 4 has been named "effective social competency" due to its high loadings on interact intellectually with my customers (.864), interact intellectually with my staff (.646) and identify goods or services customers want (.527). This factor accounted for $7.70 \%$ of the variation in the data set.

\section{Factor 5: Effective Analytical Reasoning}

This factor accounted for $7.45 \%$ of the variation in the data set. Only two variables loaded highly on this factor. They were: coordinate task effectively (.820) and understand what others mean by their words and actions (.725).

\section{Factor 6: Networking}

Two variables loaded highly on this factor. These variables were; negotiate with others (.853) and motivate my customers (.684). It accounted for $7.34 \%$ of the variation in the data set.

\section{Factor 7: Proactivity}

This factor was the least factor, it accounted for only $5.67 \%$ of the variation in the data set. This factor was named due to both the positive and negative loadings on organize resources (.791) and in dealing with our competitors, we typically initiate actions, which competitors then respond to (-.538).

Rauch and Frese (2007) conducted a similar comprehensive analysis of entrepreneurs' personality traits including a comparison with a full set of personality predictors for both start-up activities as well as success. They noted that some traits such as tenacity or passion for work, have not been studied enough to be able to include them into the meta-analyses. They concluded that traits matched to the task of running a business produced higher effect sizes with business creation than traits that were not matched to the task of running an enterprise. The traits matched to entrepreneurship significantly correlated with entrepreneurial behaviour, i.e. business creation, and business success, and these were need for achievement, generalized self-efficacy, innovativeness, stress tolerance, need for autonomy, and proactive personality. 


\section{Conclusion}

It has been revealed that competencies like proactivity, networking, and self-efficacy, willingness to take risk, creative thinking and willingness to learn were being possessed by the firm managers. Therefore, government, chambers of commerce and other non-governmental organization should regularly organize seminars for potential and actual small and medium enterprise operators where they should be educated on how to plan, organize, direct and control their businesses. Also, micro, small and medium enterprises operators' should device effective marketing strategies. This includes such promotional strategies as advertising, good customers relations management at all times

\section{References}

Aremu MA and Adeyemi SL (2011). Small and medium scale enterprises as survival strategy for employment generation in Nigeria. Journal of Sustainable Development. 4 (1): 200-206

Beckhard R and Pritchard W (1993) Changing the Essence. San Francisco: Jossey-Bass.

Bird B (1995) Towards a theory of entrepreneurial competency. Advances in Entrepreneurship, Firm Emergence and Growth Journal. 2: 51-72

Brockhaus RH (1980) Psychological and Environmental Factors which distinguish the successful from Unsuccessful Entrepreneur: A Longitudinal Study. Academy of Management Proceedings. 368-372.

Brockhaus RH (1982) The Psychology of the Entrepreneur. In Encyclopaedia of Entrepreneurship. New Jersey: Englewood Cliffs. 39-57,

Buttner EH and Rosen B (1989) Funding new business ventures: Are decision makers biased against women entrepreneurs? Journal of Business Venturing. 4: 249-261.

Central Bank of Nigeria and Bankers Committee (2001)

Cheskin (2000) Women Entrepreneurs Study. A Joint Research Project by Cheskin Research Santa Clara University Centre for Innovation \& Entrepreneurship. The Centre for New Futures. January 2000.

Covin JG and Slevin DP (1989) Strategic management of small firms in hostile and benign environments. Strategic Management Journal. 10(1): 75-88.

Dannson, Ezedinma AC, Wanmbia TR, Bashasha B, Kirsten J and Satorius K (2004) Strengthening Farm-agribusiness Linkages in Africa: Summary results of five Country Studies in Ghana, Nigeria, Kenya, Uganda and South Africa. Agricultural Management, Marketing and Finance Service (AGSF), Agricultural Support Systems Division, FAO, Rome.

Entrialgo M, Fernanderz E and Vazquez CJ (2001) The effect of organizational context on SME's entrepreneurship: some Spanish evidence. Small Business Economics. 16: 223-236.

Fasua k (2006) Entrepreneurship Theory, Strategies and Practice. Jos: Larigahic Printers.

Gabbot M and Hogg G (1997) (eds) Contemporary Services Marketing Management, London, the Dryden Press, Pp. 174-194.

Gibbs AA (2005) Towards the entrepreneurial university. Entrepreneurship education as a lever for change. National Council for Graduate Entrepreneurship (NCGE). Retrieved from www.ncge.org.uk. 
Hair JF, Anderson RE, Tatham RL and Black WC (1998) Multivariate Data Analysis ( $5^{\text {th }}$ Edition), Upper Saddle River, N. J. Prentice - Hall International Inc.

Handler WC (1994) Succession in Family Business: A Review of the Research. Family Business Review. 7(2): 133-157

King K and McGrath S (2002) Globalisation, Enterprise and Knowledge: Educational Training and Development. International Review of Education. 74-76.

Kinnear TC and Gay CD (1997) SPSS for Windows: Make Simple ( $2^{\text {nd }}$ edition), Hove, England, Psychology Press.

Man TWY, Lau T and Chan KF (2002) The competitiveness of small and medium enterprises a conceptualization with focus on entrepreneurial competencies. Journal of Business Venturing. 17:123-142

McClelland DC (1965) Need Achievement and Entrepreneurship: A Longitudinal Study. Journal of Personality and Social Psychology. 1: 389-392.

McClelland DC and Winter DG (1969) Motivating Economic Achievement. New York: The Free Press.

McGregor J and Tweed D (2001) Gender and managerial competence: support for theories of androgyny Women in Management Review. 16 (6): 279-86.

Naman JL and Slevin OP (1993) Entrepreneurship and the concept of fit: A model and empirical tests". Strategic Management Journal. 4(2): 137-153.

Nunnally JC (1978) Psychometric theory. New York: McGraw Hill.

Olajide, Ogundele, Adeoye and Akinlabi, 2008 Small and medium enterprises (SMEs): an appropriate medication for Nigeria's economic predicament in the global competitive economy. Akungba Journal of Management. 1(1\& 2):173-193.

Parasuraman A, Zeithaml VA and Berry LL (1988) SERVQUAL, A Multiple-item scale for Measuring Consumer Perception of Service Quality. Journal of Retailing. (1): $2-40$.

Prahalad CK and Hamel G (1990) The Core Competence of the Corporation. Harvard Business Review. 68(3):79-91.

Quinn, JB (1999) Strategic outsourcing: Leveraging knowledge capabilities. Sloan Management Review. 40(4): 9-22.

Rasheed HS (2002) Developing Entrepreneurial Characteristics in Youths: The Effect of Education and Enterprise Experience. International Journal of Entrepreneurship Education. 2 (1): 21-36.

Rauch A and Frese M (2007) Let's put the person back into entrepreneurship research: A meta-analysis on the relationship between business owners' personality traits, business creation and success. European Journal of Work and Organizational Psychology. 16: 353-385.

Scot M and Twoney D (1988) The long term supply of entrepreneurs: Student's career aspirations in relation to entrepreneurship. Journal of small business management. 26(4): 5-13.

Sexton DL and Bowman N (1983) Determining Entrepreneurial Potential of Student. Academy of Management Proceedings. 408-411.

Stokes D and Wilson N (2006) Small Business Management and Entrepreneurship, $5^{\text {th }}$ edition, London: Thomson.

Storey D (1982) Entrepreneurship for Small Firm. London: Groom Helm.

Tapan KP (2002) Entrepreneurial Success and Risk Perception among Small-scale Entrepreneurs of Eastern India, India". Indian Institute of Management, Lucknow Journal of Entrepreneurship. 11(2): 173-190.

Tonge J (2002) A Review of Small Business Literature, (Part 2): Birth, Growth and Death of the Small Business. Working Paper Series, Manchester Metropolitan University Business School. 
Tsai WM, MacMillan IC and Low MB (1991) Effect of strategy and environment on corporate venture success in industrial markets. Journal of Business Venturing. 6(1): 9-28.

Umoh UA (2015) Business Survival in Nigeria: A study of Uyo Metropolis. A Technical Report Submitted to the Department of Business Management, University of Uyo. 58-61.

United Nations Centre on Transnational Corporation (UNCTC, 1988) Empredore Technologies (EMPRETECC), An Entrepreneurship Training Programme developed by UNDP and UNCTC, 1988.

Weber M (1930) The Protestant Ethic and the Spirit of Capitalism, translated by Talcott Parsons, London: Allen and Unwin.

Zahra SA (1993) Environment, corporate entrepreneurship, and financial performance: a taxonomic approach". Journal of Business Venturing. 8 (4): 319-340. 